\title{
The Design of Drawing Process of Cylindrical Cup with Oval Bottom Using Computer Simulation
}

\author{
Mária Kapustová and Róbert Sobota \\ Slovak University of Technology in Bratislava, Faculty of Materials Science and Technology in Trnava, Institute of Production Technologies, \\ J. Bottu 25, 91724 Trnava, Slovakia
}

\begin{abstract}
Based on technological calculations, technology of one-operation drawing without blankholder was designed for production of a large-dimensional drawpiece with shape of welded on concave bottom. The necessary drawing force was also defined by calculation as maximum drawing force for trimming of drawpiece bottom. This contribution points out to the importance of FEM simulation of drawing process in order to verify the design of production technology of drawpiece with shape of welded on concave bottom on the basis of technological calculations. Simulation programme Deform verified the construction design of drawing tool determined for drawpiece production by first draw, and also determined the drawing force actually consumed during plastic deformation of drawpiece shape. Used simulation software confirmed correctness of drawing tool construction, as correct material plastic flow in drawing tool was monitored and production of drawpiece was faultless.
\end{abstract}

\section{Introduction}

Seamless steel piping parts (pipe fittings) are widely used in various technical equipment as e.g. steam boilers, pressure vessels, containers, as well as steam, gas and petroleum piping, etc., which are applied at concurrent effect of temperature and pressure. One of essential properties of pipe fittings is condition of their weldability. These pipe fittings are represented also by welded on concave bottoms that are used for ending of piping or as a part of exterior casing of small and large pressure vessels, containers, cisterns, etc. Welded on concave bottoms with various diameters and wall thickness are produced by cold drawing using hydraulic presses. Production of drawpieces with required dimensions may be realized by first or more draws within drawing with or without blank holder.

The drawing tool consists of a die and a punch which are made of alloy tool steel and produced by chip machining with subsequent heat treatment. Mentioned heat treatment comprises of hardening and tempering at low temperatures. At construction of drawing tool a drawing clearance between the die and the punch is important, whereby the dimension of this clearance depends on thickness of drawn metal sheet [1]-[5].

\section{Description of drawing material and construction of draw piece shape}

The selection of appropriate material for drawpieces determined for steel piping parts (pipe fittings) is important for correct, faultless production of drawpieces.
The most common material used for production of welded on concave bottoms is high-temperature strong steel sheet hot rolled which has guaranteed ductility. From the aspect of shape the designed drawpiece belongs to cylindrical large-dimensional drawpieces with oval bottom, i. e. with simple shapes. Actual drawpiece with welded on concave bottom shape illustrated on Fig. 1 will be made of steel 13CrMo4-5. The mentioned steel belongs to a group of chrome-molybden high-temperature strong steels which are appropriate to use at increased temperatures up to $560^{\circ} \mathrm{C}$. Therefore these steels are used mainly for production of seamless tubes, component parts for steam boilers and steam turbines.

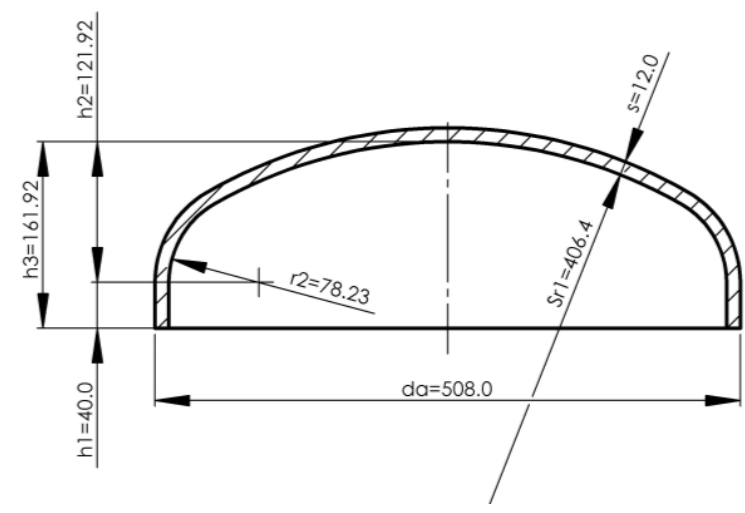

Figure 1. Shape and dimensions of drawpiece.

Low-carbon alloy steel $13 \mathrm{CrMo} 4-5$ has guaranteed weldability, good machinability and also hot and cold formability. Steel material is supplied in a state after heat treatment, i. e. normalizing at $890-950^{\circ} \mathrm{C}$ and tempering at $630-730^{\circ} \mathrm{C}$. Mechanical properties of steel are as 
follows: yield point $\mathrm{R}_{\mathrm{p} 0,2}=\min .300 \mathrm{MPa}$, tensile strength $\mathrm{R}_{\mathrm{m}}=450-600 \mathrm{MPa}$ and percent elongation $\mathrm{A}=\min .19 \%$. Chemical composition of steel 13CrMo45 is described in Table. 1.

Table 1. Chemical composition of steel 13CrMo4-5 (wt \%).

\begin{tabular}{|l|l|l|l|l|l|l|}
\hline Element & & $\mathrm{C}$ & $\mathrm{Mn}$ & $\mathrm{Si}$ & $\mathrm{Cr}$ & $\mathrm{Cu}$ \\
\hline \multirow{2}{*}{ Composition } & $\min$ & 0,08 & 0,40 & 0,35 & 0,70 & 0,30 \\
& $\max$ & 1,18 & 1,00 & & 1,15 & \\
\hline & & $\mathrm{Mo}$ & $\mathrm{N}$ & $\mathrm{P}$ & $\mathrm{S}$ & \\
\hline & $\min$ & 0,40 & 0,012 & 0,025 & 0,010 & \\
& $\max$ & 0,60 & & & & \\
\hline
\end{tabular}

\section{Calculation of the draw process parameters}

In order to produce the cylindrical cup with oval bottom according to dimensions as stated in Fig. 1, first it is necessary to determine the dimension of workpiece (blank) by calculation. The workpiece prepared out of the metal sheet will be circular-shaped with wall thickness $\mathrm{s}$ $=12.0 \mathrm{~mm}$ and its size (diameter) will be defined by following relation:

$$
D=\sqrt{d_{a}^{2}+4 .\left(h_{2}^{2}+d_{a} \cdot h_{1}\right)}+w=667.5 \mathrm{~mm}
$$

where: $d_{a}$ - external diameter of drawpiece [mm], $\mathrm{h}_{1}$ height of cylindrical part $[\mathrm{mm}], \mathrm{h}_{2}$-height of oval bottom $[\mathrm{mm}], \mathrm{w}-$ allowance for trimming $[\mathrm{mm}$, $\mathrm{W}=(2 \div 5) . \mathrm{s}=3.12=36 \mathrm{~mm}$.

Diameter dimension of circular-shaped workpiece is $\mathrm{D}=670.0 \mathrm{~mm}$.

In order to determine number of draws necessary for production of this drawpiece the calculation of total drawing ratio is essential. The production of drawpiece with oval bottom will be one-operational as the real value of total drawing ratio is smaller than the allowable value for the first draw. For consideration of the blankholder necessity the relation according to the author Šfman [6] is used. This relation recommends drawing without blankholder if the following condition is fulfilled:

$$
\begin{aligned}
& D-d_{a} \leq 18 . s \\
& 670-508 \leq 18.12
\end{aligned}
$$

For the condition $162 \leq 216$ the blankholder is not necessary.

For definition of the drawing force needed for oneoperational production of drawpiece with oval bottom the relation for calculation of maximum drawing force is commonly used:

$$
\mathrm{F}_{\mathrm{tmax}}=\mathrm{S} \cdot \mathrm{R}_{\mathrm{m}} \cdot \mathrm{K}_{\mathrm{t}}
$$

where: $R_{m}$ - tensile strength of steel 13CrMo4-5 $\left(R_{m}=450 \mathrm{MPa}\right), K_{t}$ - coefficient depending on the draw ration for the first draw $\left(\mathrm{K}_{\mathrm{t}}=1.0\right), \mathrm{S}$ - perforated drawpiece area $\left(\mathrm{S}=18698.7 \mathrm{~mm}^{2}\right)$

$$
\mathrm{F}_{\text {tmax }}=18699.450 .1=8414550 \mathrm{~N} \approx 8414 \mathrm{kN}
$$

The calculation of drawing force through the abovementioned Eq. (3) is not accurate (only informative), as calculated force value is maximal, needed for damage of drawpiece, i. e. for tearing of its bottom. Therefore it is necessary to verify by computer simulation the correctness of the technology design of one-operational drawing of particular drawpiece and determine the real value of the drawing force needed for drawpiece production.

\section{Computer simulation of material plastic flow in drawing tool using programme deform}

Computer simulation of drawing process regarding steel alloy $13 \mathrm{CrMo} 4-5$ was performed through the programme DEFORM-3D (Design Environment for FORMing). It is a high-performance FEM simulation system designed for three-dimensional (3D) analysis of material flow within broad scope of forming processes. It is a practical and effective tool for prediction of plastic material flow in forming tools for the purpose of reduction of production costs and acceleration of the whole production process.

It is used for FEM simulation of drawing, die forging and smith forging processes, rolling, extruding, etc. This programme is suitable for simulation of forming processes with regard to hot, warm and also cold forming [5]-[9]

User environment of programme Deform contains two dialog windows illustrated in Fig. 2.

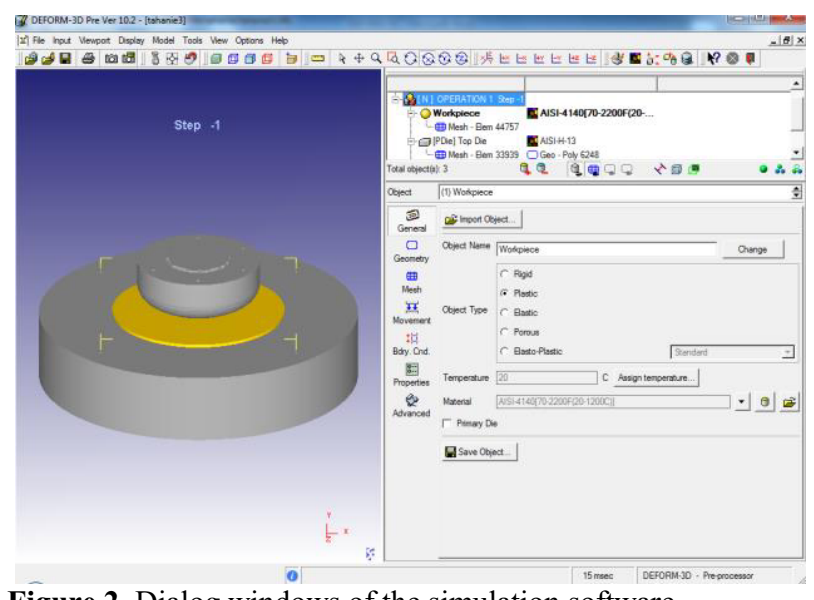

Figure 2. Dialog windows of the simulation software DEFORM 3D.

After definition of input conditions e.g. process type (drawing), number of objects, objects type, import geometry, temperature, mesh, material type, boundary conditions, movement (hydraulic press), contact (Coulomb coefficient of friction 0.2) and simulation controls a database of information necessary for initiation of drawing process simulation was generated [10]-[12]. Numeric simulation verified the correctness of design of technological conditions concerning drawing process and the correctness of drawing tool construction. Based on Fig. 3 the correct material plastic flow is evident and the drawpiece shape was faultless. 


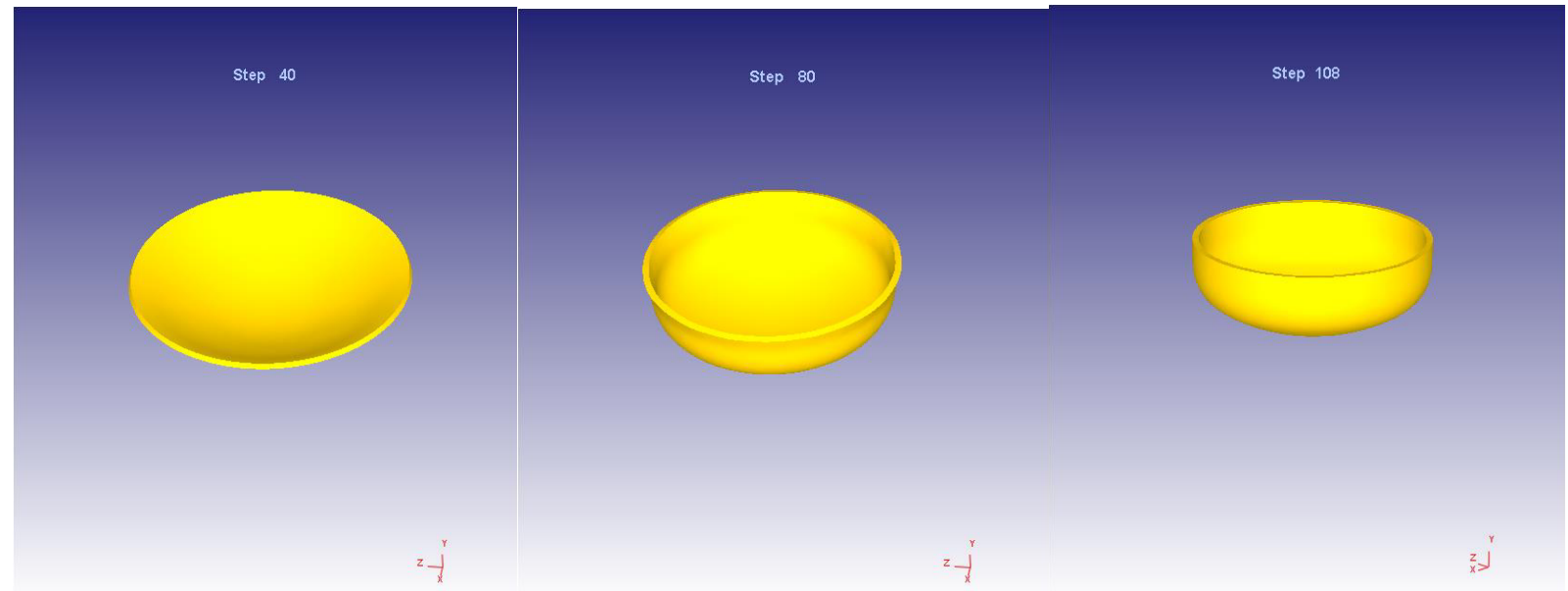

Figure 3. Simulation of plastic deformation of the drawpiece with shape of welded on concave bottom.

The results of output phase, i.e. simulation postprocessing, are the courses of effective strain and temperature fields in a final shape drawpiece shown on Fig. 4, Fig. 5.

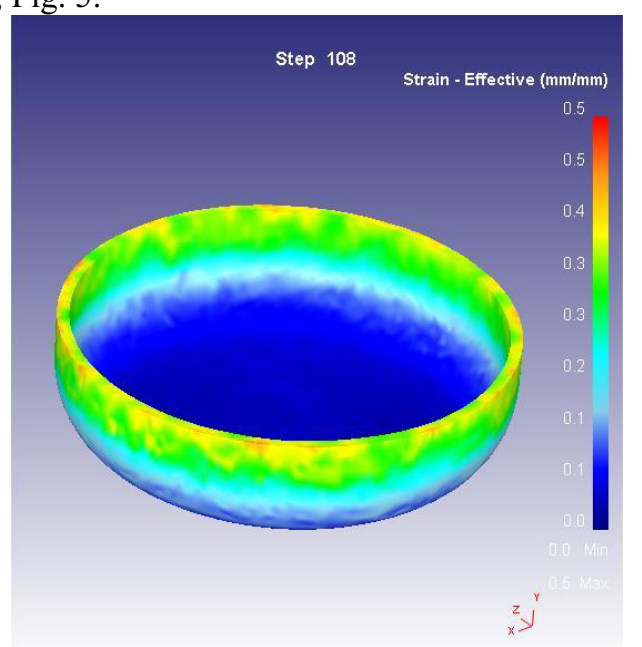

Figure 4. Course of effective strain in final shape drawpiece.

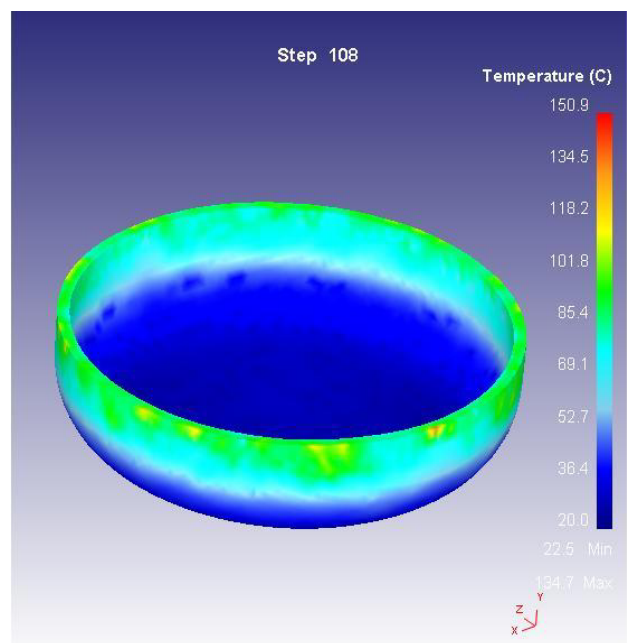

Figure 5. Temperature fields in final shape drawpiece.

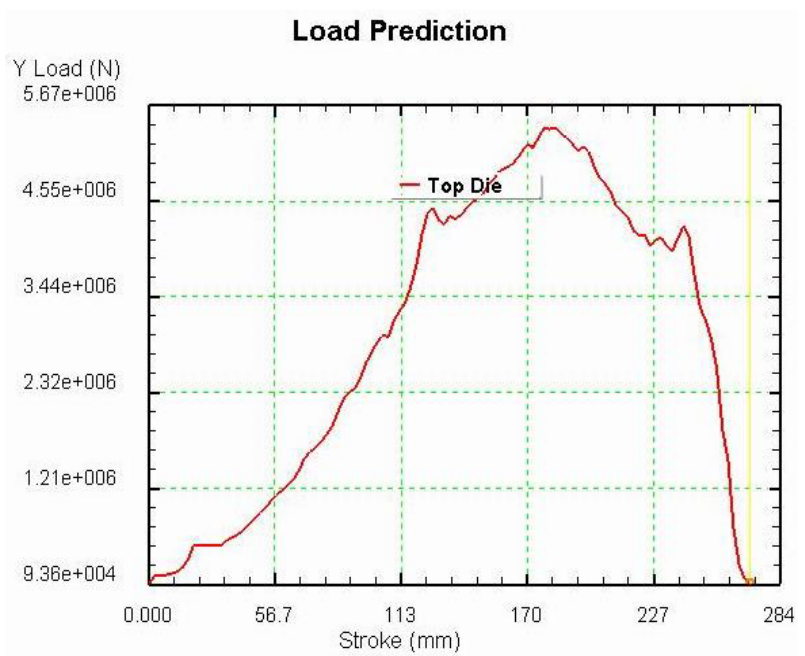

Figure 6. Graphic course of drawing force during a press stroke.

The course of drawing force illustrated on Fig. 6 is an important result of simulation which is necessary for the selection of appropriate hydraulic press for the production of given drawpiece.

\section{Summary}

Achieved results of FEM simulation of drawing process regarging the drawpiece with oval bottom show correctness of production technology design and geometry of drawing tool without blankholder. Material plastic flow was optimal and final shape of drawpiece did not show any visible defects on its surface. From the course of drawing force based on the drawing process simulation it results that maximum force value is approx. $5500 \mathrm{kN}$. This force value was achieved at about $65 \%$ of hydraulic press stroke and represents real value compared to the calculated force value of $8400 \mathrm{kN}$. The course of drawing force detected by numeric simulation will be a valuable assistance in selection of the appropriate press for production of the given drawpiece under practical conditions. 


\section{Acknowledgment}

This article has been created with the support of projects VEGA No. 1/0669/15 and Form Tool MANUNET-2014-11283 and was supported also by the Slovak Research and Development Agency under the Contract No.APVV-15-0319.

\section{References}

1. W.F. Hosford, R.M. Caddell, Metal Forming: Mechanics and Metallurgy, 4. ed., Cambridge University Press, New York, p. 331, (2011).

2. I. Görögová, Technological heredity in bearing production, 1st ed., Scientific Monographs, Aleš Čeněk, Plzeň, p. 69, (2016).

3. G. Gantar, A. Sterzing, Robust design of forming processes, Journal of Mechanical Engineering, 54, p. 249-257, (2008).

4. M. Ridzoň, The Effect of Technological Parameters Influencing the Properties of Seamless Cold-Drawn Tubes, 1st ed., Scientific Monographs, Hochschule Anhalt, Köthen, p. 89, (2012).

5. E. Spišák, Mathematical modeling and simulation of technological processes - Drawing, TYPO Press, Košice, p. 156, (2000).
6. M. Forejt, M. Píška, Theory of forming, machining and tools, CERM, Brno, p. 225, (2006).

7. P.M. Dixit, U.S. Dixit, Modeling of Metal Forming and Machining Processes by Finite Element and Soft Computing Methods, Springer Verlag, London, p. 590, (2008)

8. S. Kobayashi, S.I. Oh, T. Altan, Metalforming and the Finite-Element Method, Oxford University Press, London, p. 402, (1989).

9. Edward R. Champion, Jr., Finite Element Analysis in Manufacturing Engineering, McGraw-Hill, New York, p. 310, (1992).

10. S. Natarajan, S. Venkataswamy, P. Bagavathiperumal, A note on deep drawing process: numerical simulation and experimental validation, Journal of Material Processing Technology, 127(1), p. 64-67, (2002).

11. D.M. Neto, M.C. Oliveira, J.L. Alves, L.F. Menezes, Influence of the plastic anisotropy modelling in the reverse deep drawing process simulation, Materials and Design, 60, p. 368-379, (2014).

12. G. Ferran, A.C. de Moura, L.P. Moreira, Computer aided development of a bending-drawing test for thin metallic sheets, Journal of Material Processing Technology, 80-81, p. 531-537, (1998). 